\title{
RESEARCH OF HEAT EXCHANGE PROCESSES AT LIQUIDS BOILING ON EXTENDED AND ROUGH SURFACES
}

\author{
Vitali Litvinenko, Aleksandr Shapovalov \\ Scientific Supervisor A.V. Ovsyannik, PhD. in Engineering Science
}

Boiling processes on extended and rough surfaces are getting ever more widespread for transfer of highly dense thermal flows in various fields of technology (predominantly in nuclear power engineering, metallurgy).

The idea of using a rib in boiling liquid lies in the fact that even at temperatures conforming to the film boiling the combined heat flux transferred by a rib remains on a high level due to heat transfer with heat conductivity to the areas of intensive heat transfer (close-to-critical fields of bubble and transient boiling).

Find below the results of experimental data for boiling of pure Freon-12 on horizontal ribbed tubes with various ribbing geometry (table 1).

In table $1 d_{e}-$ main diameter of tubes; $D_{H}-$ external diameter of a rib; $d_{B H}-$ internal diameter of tubes; $S_{p}$ - pitch of a rib; $\alpha$ - rib angle; $\delta_{C P}$ - average rib thickness; $F_{H}$ - full external surface of tubes; $F_{B H}$-internal surface of tubes; $G$ weight of 1 running meter of tubes; 1 - length of the experimental section.

Table 1

\begin{tabular}{|l|l|l|l|l|l|l|l|l|l|l|l|l|l|l|}
\hline $\begin{array}{l}\text { Tube } \\
\text { No. }\end{array}$ & $\begin{array}{l}\text { Type of } \\
\text { tube }\end{array}$ & $\begin{array}{l}\mathrm{d}_{\mathrm{o}} \\
\mathrm{mm}\end{array}$ & $\begin{array}{l}\mathrm{d}_{\mathrm{BH}} \\
\mathrm{mm}\end{array}$ & $\begin{array}{l}\mathrm{D}_{\mathrm{H}} \\
\mathrm{mm}\end{array}$ & $\begin{array}{l}\mathrm{S}_{\mathrm{p}} \\
\mathrm{mm}\end{array}$ & $\alpha$ & $\begin{array}{l}\delta_{0} \\
\mathrm{~mm}\end{array}$ & $\begin{array}{l}\delta_{\mathrm{r}} \\
\mathrm{mm}\end{array}$ & $\begin{array}{l}\delta_{\mathrm{CP}} \\
\mathrm{mm}\end{array}$ & $\begin{array}{l}\mathrm{F}_{\mathrm{H}}, \\
\mathrm{m}^{2} / 1 \mathrm{~m}\end{array}$ & $\begin{array}{l}\mathrm{F}_{\mathrm{BH}}, \\
\mathrm{m}^{2} / 1 \mathrm{~m}\end{array}$ & $\begin{array}{l}\mathrm{F}_{\mathrm{H}} / \mathrm{F} \\
\mathrm{BH}\end{array}$ & $\mathrm{G} / \mathrm{F}_{\mathrm{H}}$ & $1 / \mathrm{m}^{2}$ \\
\hline 1 & thread & 16.5 & 13.2 & 21 & 2 & 35 & 1.5 & 0.3 & 0.9 & 0.145 & 0.0145 & 3.5 & 9.5 & 0.4 \\
\hline 2 & $\begin{array}{l}\text { with } \\
\text { straight } \\
\text { circular } \\
\text { fins }\end{array}$ & 17.55 & 12 & 24.475 & 1.413 & - & 0.85 & 0.85 & 0.85 & 0.39 & 0.0377 & 10.35 & 7.65 & 0.4 \\
& & & & & & & & & & & & & & \\
\hline
\end{tabular}

An experimental unit was created, which makes it possible to make experiments in the range of thermal loads $\mathrm{q}=500-20000 \mathrm{~W} / \mathrm{m}^{2}$ (for smooth pipe $\mathrm{q}=$ $500-40000 \mathrm{~W} / \mathrm{m}^{2}$ and boiling temperatures 
$\mathrm{t}_{0}=-30+20^{\circ} \mathrm{C}$

According to schedules, heat transfer coefficients during Freon-12 boiling are much higher on ribbed surface $\alpha_{\mathrm{p}}$ than on smooth surface $\alpha_{\Gamma л}$ (fig. 1-2).

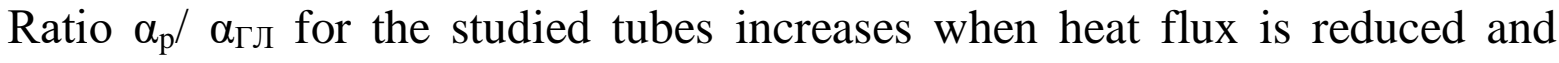
boiling temperature drops, it is especially high under conditions typical for operation of evaporators of refrigerators.

Heat transfer intensity increase during boiling on ribbed tubes is connected with peculiar conditions of origin, growth and bubbles detachment as compared with smooth ones.

Visual observations showed that that inception of bubbles occurs near the base of ribs. This is explained by the fact that in places of connection of ribs with the tube they are moistened worse, and therefore, density of the heat flux transferred from the given area is more important.

As it is shown in figure 1, tube №. 2, having the smallest distance between ribs, is most effective as compared with tube №. 1 at low temperatures of boiling. Its advantage becomes lower, when temperature of boiling rises. In this case heat transfer surface is steamed due to generation of a steam film near the base of ribs. On the basis of the aforesaid it may be concluded that tubes of evaporators operated on Freon-12 within the range of temperatures $t_{0}=0+-30^{\circ} \mathrm{C}$ should have the distance between ribs $0.3-0.5 \mathrm{~mm}$, which is commensurable with the values of diameters of bubbles at departure under these conditions.

Application of porous metal coatings is the most effective and reliable method of heat transfer intensification during boiling.

Consider the experimental data received at the unit, where experimental specimens were made of stainless steel having parameters shown in table 2. Heat transfer during propane boiling was studied within the range of $\mathrm{q}=0.1-100 \mathrm{~kW} / \mathrm{m}^{2}$, temperatures from -10 to $+40^{\circ} \mathrm{C}$.

First evaporation centres occurred in upper rough pipe sections on smooth pipes with rough surface (specimens $B$ and $S$ ) and on pipes with porous coating. 
When thermal loading increases, the situation becomes similar to boiling on a polished pipe, however, heat transfer intensity is 2.5-3 times higher than on smooth pipes (fig. 3). Strong screening of the pipe surface with steam bubbles was observed in the field of $q>20-30 \mathrm{~kW} / \mathrm{m}^{2}$, and heat transfer growth intensity reduced. Hysteresis of heat flux was strongly expressed.

Table 2

\begin{tabular}{|l|l|l|l|l|l|l|l|l|}
\hline $\begin{array}{l}\text { Specimen } \\
\text { No. }\end{array}$ & A & B & S & 5 & 6 & 7 & 2 & 3 \\
\hline$\delta, \mathrm{mm}$ & $\begin{array}{l}\text { smooth } \\
\text { surface }\end{array}$ & $\begin{array}{l}\text { smooth } \\
\text { surface }\end{array}$ & $\begin{array}{l}\text { smooth } \\
\text { surface }\end{array}$ & 0.1 & 0.15 & 0.3 & 0.2 & 0.1 \\
\hline$\varepsilon, \%$ & $\begin{array}{l}\text { abrasive } \\
\text { paper } \\
\mathrm{R}_{\mathrm{z}}=1.3 \mu \mathrm{m}\end{array}$ & $\mathrm{R}_{\mathrm{z}}=4 \mu \mathrm{m}$ & shot cleaning & 12.31 & 12.73 & 12.83 & 12.59 & 12.74 \\
& & & & & & & & \\
\hline
\end{tabular}

Coating thickness and its porosity had impact on heat transfer intensity. Maximal heat transfer was observed in specimen №. $2(\delta=0.2 \mathrm{~mm})$ in specimens having the same coating porosity. Coating thickness increase up to $0.3 \mathrm{~mm}$ resulted in heat transfer reduction. Coating porosity reduction from 12.8 to $4.3 \%$ considerably reduces heat transfer.

The conducted research has shown that application of porous metal coatings on the heat transfer surface makes it possible to considerably (by 3-5 times in the field of low thermal loads, $\mathrm{q}\left(8 \mathrm{~kW} / \mathrm{m}^{2}\right.$ and by $2.5-3$ times in the field of high, $\left.\mathrm{q}>8 \mathrm{~kW} / \mathrm{m}^{2}\right)$ increase heat transfer intensity during propane boiling on horizontal pipes. The best results were obtained for coatings having thickness about $0.2 \mathrm{~mm}$ and porosity about $12.5 \%$. 


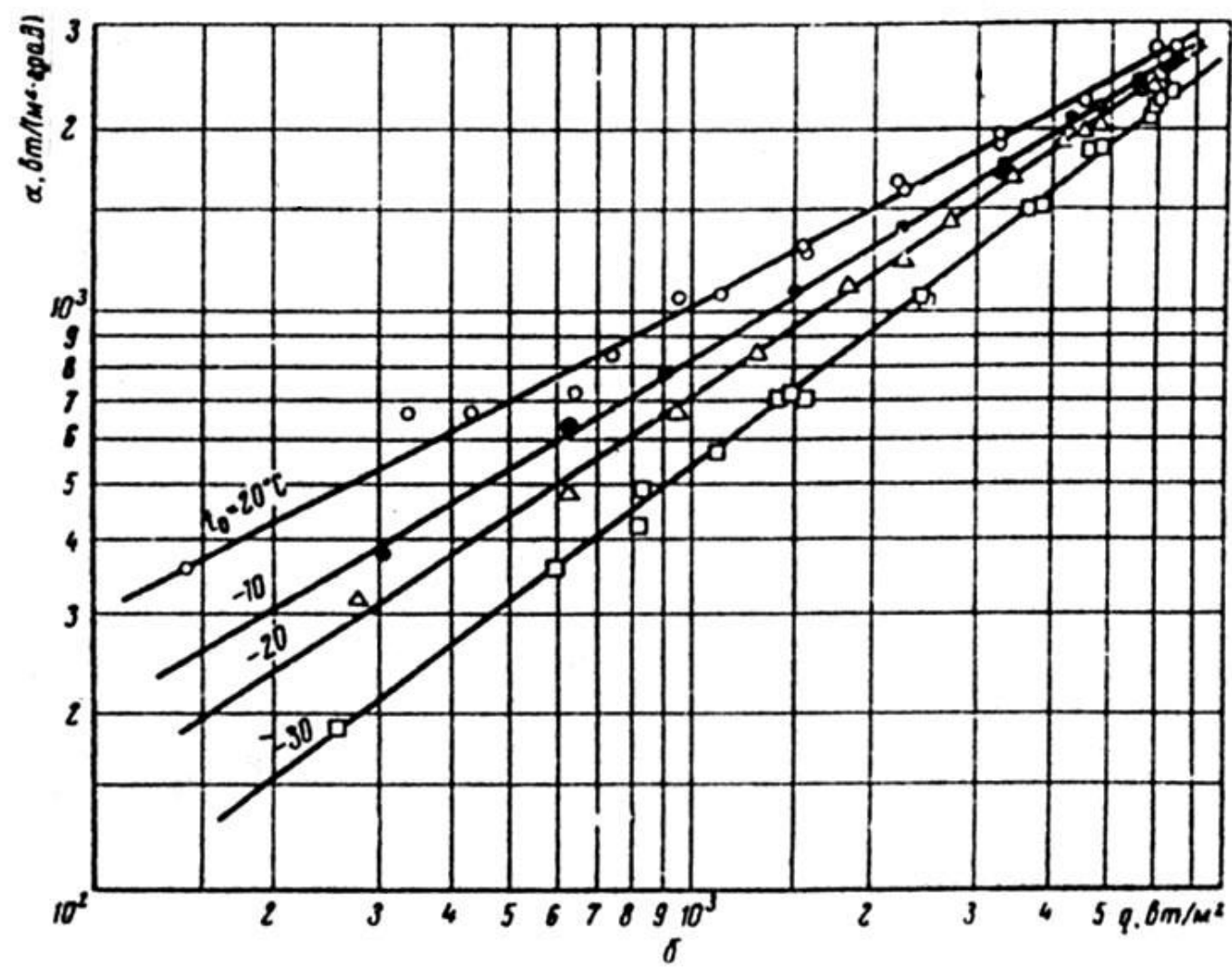

Fig.1. Dependence $\alpha=f(q)$ at Freon-12

boiling on ribbed tube № 2

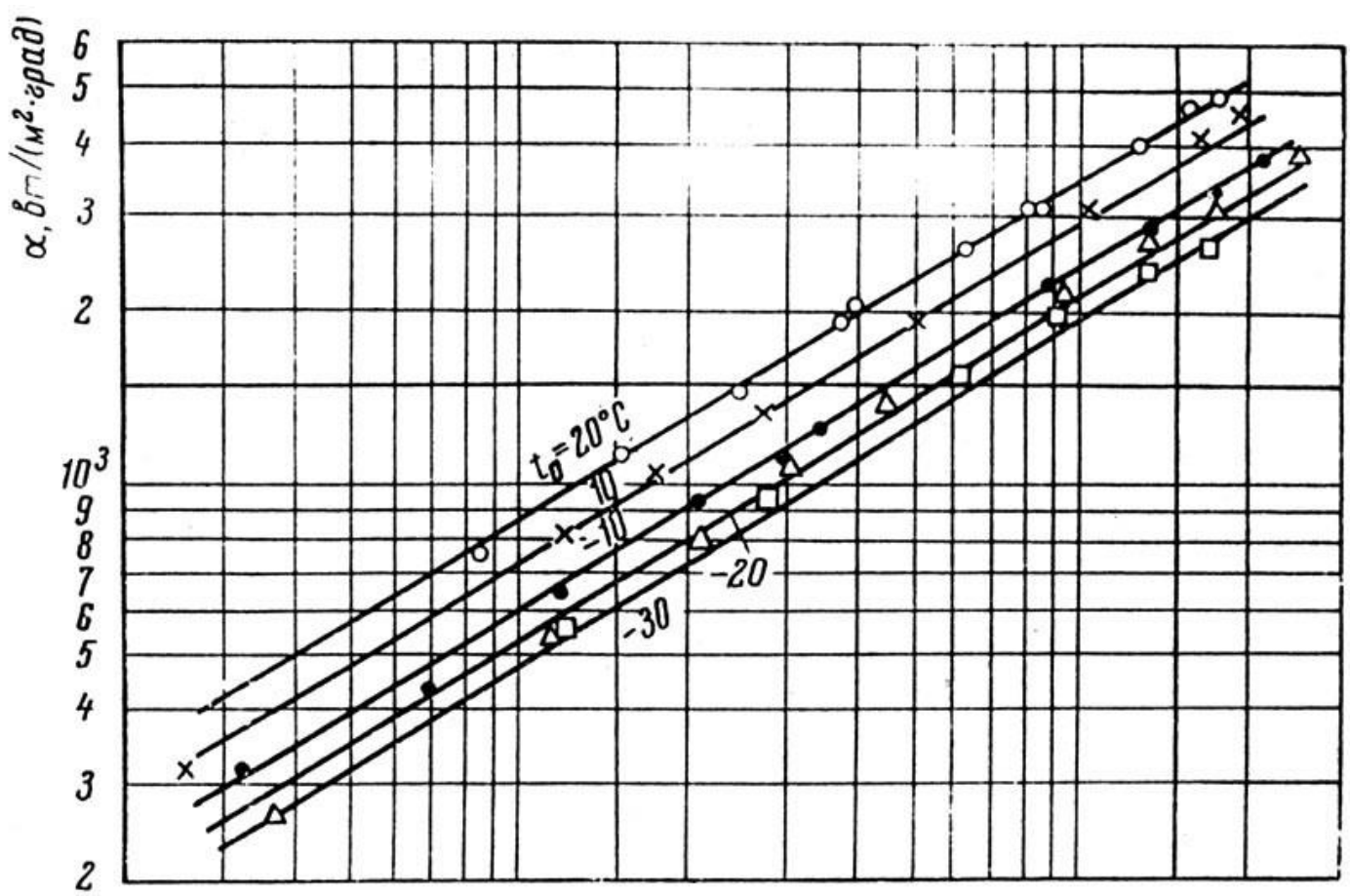

Fig. 2. Dependence $\alpha=f(q)$ at Freon-12

boiling on ribbed tube №. 1 

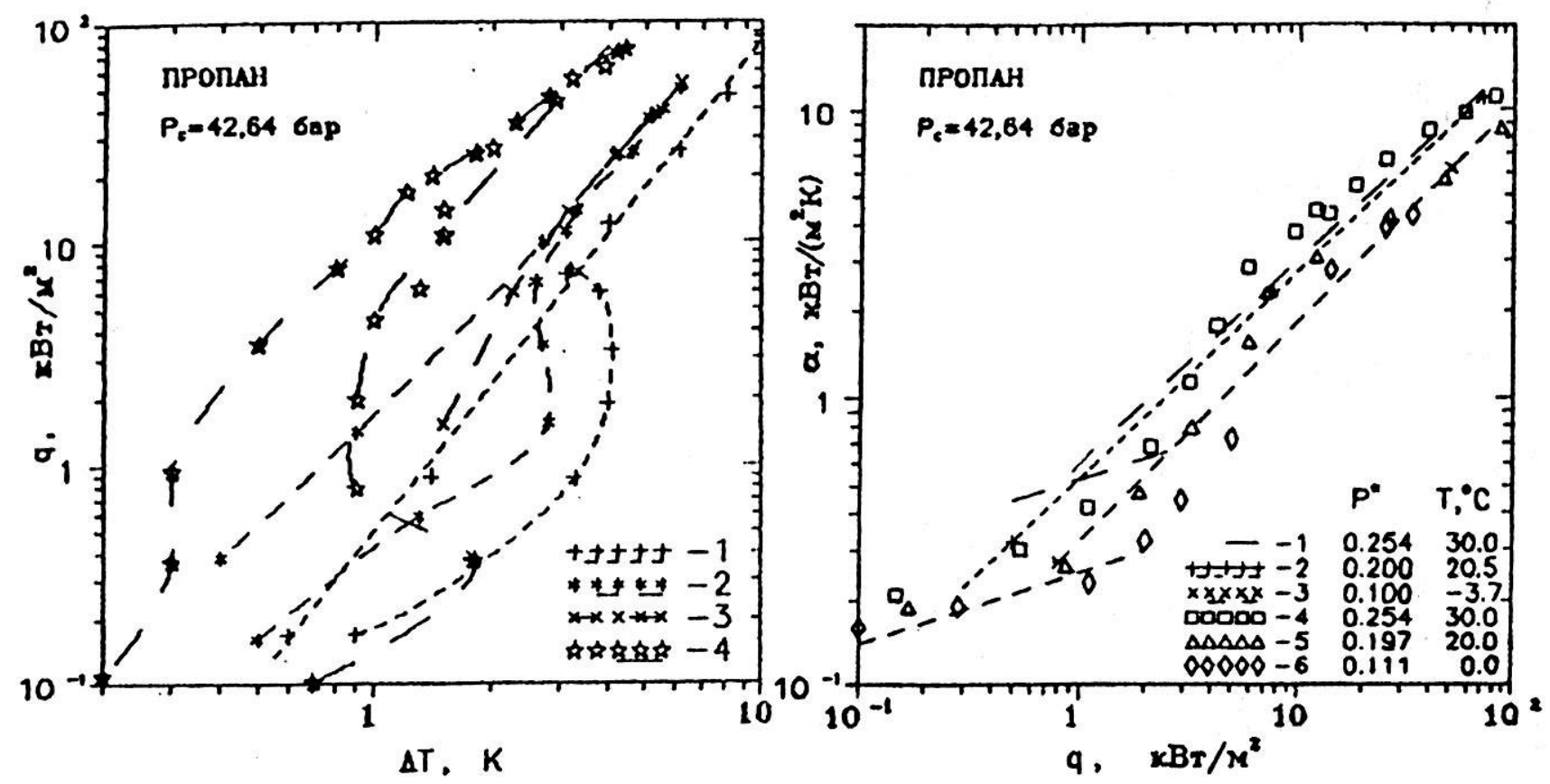

Fig. 3. On the left: typical curves of propane boiling on pipes with different external surface, T=293K: 1 -specimen A; 2-S; 3-B; 4 - №. 7. On the right: comparison on results of propane boiling on smooth pipes: 1- [6]; 2, 3- [5]; 4-6-specimen A 